\title{
Sodium bicarbonate supplementation and the female athlete: a brief commentary with small scale systematic review and meta-analysis.
}

\author{
SAUNDERS, B., FARIAS DE OLIVEIRA, L., DOLAN, E., DURKALEC- \\ MICHALSKI, K., MCNAUGHTON, L., ARTIOLI, G.G. and SWINTON, P.A.
}

This is an Accepted Manuscript version of the following article, accepted for publication in European Journal of Sport Science. SAUNDERS, B., DE OLIVEIRA, L.F., DOLAN, E., DURKALEC-MICHALSKI, K., MCNAUGHTON, L., ARTIOLI, G.G. and SWINTON, P.A. 2022. Sodium bicarbonate supplementation and the female athlete: a brief commentary with small scale systematic review and meta-analysis. European journal of sport science [online], 22(5): nutrition for female athletes, pages 745-754. Available from:

https://doi.org/10.1080/17461391.2021.1880649. It is deposited under the terms of the Creative Commons Attribution-NonCommercial License (http://creativecommons.org/licenses/by-nc/4.0/) which permits noncommercial re-use, distribution, and reproduction in any medium, provided the original work is properly cited. 
1 Sodium bicarbonate supplementation and the female athlete: A brief commentary with

\section{small scale systematic review and meta-analysis}

Running head: Sodium bicarbonate and the female athlete

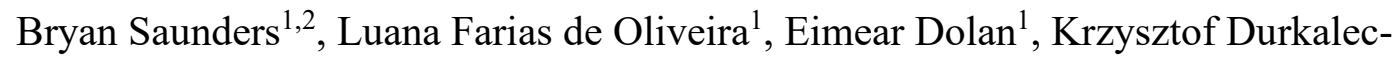
Michalski $^{3,4}$, Lars McNaughton ${ }^{5}$, Guilherme Giannini Artioli ${ }^{1}$, Paul Alan Swinton ${ }^{6}$ (1)

${ }^{1}$ Applied Physiology and Nutrition Research Group, School of Physical Education and Sport; Rheumatology Division; Faculdade de Medicina FMUSP, Universidade de Sao Paulo, Sao Paulo, SP, BR, University of São Paulo, SP, BR.

${ }^{2}$ Institute of Orthopaedics and Traumatology, Faculty of Medicine FMUSP, University of São Paulo, Brazil.

${ }^{3}$ Department of Dietetics, Poznań University of Physical Education, Poznań, Poland.

${ }^{4}$ Department of Human Nutrition and Dietetics, Poznań University of Life Sciences, Poznań, Poland.

${ }^{5}$ Sports Nutrition and Performance Group, Department of Sport and Physical Activity, Edge Hill University, Ormskirk, United Kingdom.

${ }^{6}$ School of Health Sciences, Robert Gordon University, United Kingdom.

\section{Correspondence:}

Dr Bryan Saunders

Applied Physiology \& Nutrition Research Group, Rheumatology Division, Faculty of Medicine FMUSP, Av. Dr. Arnaldo, 455 - Cerqueira César - CEP: 01246903

University of São Paulo, São Paulo, SP, Brazil.

E-mail: drbryansaunders@outlook.com

Phone: +55 11 3061-8789

Fax: +55 113813-5921 
ABSTRACT

Sodium bicarbonate (SB) is considered an effective ergogenic supplement for improving highintensity exercise capacity and performance, although recent data suggests that women may be less amenable to its ergogenic effects than men. Currently, an apparent paucity of data on women means no consensus exists on whether women benefit from SB supplementation. The aim of the current study was to quantify the proportion of the published literature on SB supplementation that includes women, and to synthesise the evidence regarding its effects on blood bicarbonate and exercise performance in women by performing a systematic review and meta-analysis. Electronic searches of the literature were undertaken using three databases (MEDLINE, Embase, SPORTDiscus) to identify relevant articles. All meta-analyses were performed within a Bayesian framework. A total of 149 SB articles were identified, 11 of which contained individual group data for women. Results indicated a pooled blood bicarbonate increase of 7.4 [ $95 \% \mathrm{CrI}$ : 4.2 to $10.4 \mathrm{mmol} \cdot \mathrm{L}^{-1}$ ] following supplementation and a pooled standardised exercise effect size of 0.37 [ $95 \% \mathrm{CrI}$ : -0.06 to 0.92 ]. The SB literature is skewed, with only $20 \%$ (30 studies) of studies employing female participants, of which only 11 studies (7.4\%) provided group analyses exclusively in women. Despite the small amount of available data, results are consistent in showing that SB supplementation in women leads to large changes in blood bicarbonate and that there is strong evidence for a positive ergogenic effect on exercise performance that is likely to be small to medium in magnitude.

Keywords: Ergogenic aid, anaerobic capacity, acidosis, glycolysis, sex differences, highintensity exercise. 
Sodium bicarbonate is considered an effective ergogenic supplement (Maughan et al., 2018), with repeated meta-analytical data supporting its use for improving high-intensity exercise capacity and performance (Carr, Hopkins, \& Gore, 2011; Christensen, Shirai, Ritz, \& Nordsborg, 2017; Matson \& Tran, 1993; Peart, Siegler, \& Vince, 2012). This is due to an increase in blood $\mathrm{pH}$ and circulating bicarbonate concentration (i.e., alkalosis) following ingestion, augmenting the buffering potential of the body. This increased buffering capacity can improve control of exercise-induced metabolic acidosis, characterized by hydrogen ion $\left(\mathrm{H}^{+}\right)$accumulation that is detrimental to exercise performance due to its interference with several metabolic and contractile processes (Allen, Lamb, \& Westerblad, 2008; Fitts, 1994; Jarvis, Woodward, Debold, \& Walcott, 2018; Sundberg, Hunter, Trappe, Smith, \& Fitts, 2018). 
77 following SB supplementation in men, but not women (Durkalec-Michalski, Zawieja, Zawieja, Michalowska, \& Podgorski, 2020). These results imply a potential sex dysmorphism that the authors attributed to the aforementioned differences in anaerobic capacities. Carr et al. (2011) previously showed unclear evidence of a modifying of sex for SB while conflicting evidence regarding the efficacy of SB to improve exercise outcomes in women exists, with both positive

82 (Delextrat et al., 2018; McNaughton, Ford, \& Newbold, 1997) and null (Macutkiewicz \& Sunderland, 2018; Voskamp, van den Bos, Foster, de Koning, \& Noordhof, 2020) results reported. These inconsistent findings appear to contrast with the strong evidence of a positive effect previously reported in studies with predominantly male participants (Carr et al., 2011; Christensen et al., 2017; Matson \& Tran, 1993; Peart et al., 2012). Disparity in the quantity of

87 data available for women compared to men might contribute to the current uncertainty and it is important to quantify and summarise current evidence for SB in women. Therefore, the aim of the current study was to quantify the proportion of the published literature on SB supplementation that includes women and to synthesise the evidence regarding its ergogenic effect on women, using a systematic review and meta-analytic approach. 


\section{Methods}

\section{Study Eligibility}

The protocol for this study was designed in accordance with Preferred Reporting Items for Systematic Reviews and Meta-Analyses (PRISMA) guidelines (Moher, Liberati, Tetzlaff, Altman, \& Group, 2009) and the research question determined with reference to PICOS (Population, Intervention, Comparator, Outcomes and Study Design). The study was not preregistered. Initially, the literature was screened to identify all SB supplementation studies with both male and female populations. This broader screening strategy was used to identify the proportion of the total evidence base that employed female participants. The data extraction and meta-analysis was subsequently based only on those studies that included a group consisting of women only. The intervention must have employed an acute ( $<1$ day) or chronic ( $>1$ day) supplementation protocol with $\mathrm{SB}$ prior to performing an exercise test. The comparator for the meta-analysis determined that only single or double-blinded, placebocontrolled studies were included. Studies that reported on outcomes based on exercise performance and capacity tests were considered for inclusion (Saunders et al., 2017) and study design allowed both crossover and parallel group designs. Only peer-reviewed, English language, original human studies were included.

\section{Search Strategy}

An electronic search of the literature was undertaken using three databases (MEDLINE, Embase, SPORTDiscus) to identify relevant articles. The search was originally conducted to inform a systematic review and meta-analysis on the use of extracellular buffers on exercise outcomes. The search terms "sodium bicarbonate", "sodium citrate", "calcium lactate", "sodium lactate" and "alkalosis" were individually concatenated with "supplementation", "exercise", "training", "athlete" and "performance". Following duplicate removal, a 2-phase 
search strategy (title/abstract; full text) was employed by two independent reviewers (LFO and ED) using freely available software - Rayyan QCRI (Ouzzani, Hammady, Fedorowicz, \& Elmagarmid, 2016). A final search was completed in February 2020.

\section{Certainty in cumulative outcomes}

122 Certainty in blood and exercise outcomes was determined according to the framework provided by the Grading of Recommendations, Assessment, Development and Evaluations (GRADE) working group (Guyatt et al., 2008). This approach considers eight factors to determine the level of certainty in outcomes, five of which can be used to downgrade certainty in outcomes (risk of bias, imprecision, inconsistency, indirectness and publication bias), while potential upgrading factors can include large effects; evidence of dose-response or the presence of plausible residual confounding factors. All studies in the current review were initially defined as "high" because they were all randomized, blinded, placebo-controlled trials. This a-priori rating was either maintained, or downgraded following application of the strategy, allowing certainty in outcomes to be graded as "high", "moderate", "low" or "very low". Risk of bias was assessed using the most recent Cochrane tool for assessing risk of bias in randomized trials (RoB 2) (Sterne et al., 2019). Evaluation of risk of bias was performed in a blinded fashion by a single reviewer (LFO) and verified by a second reviewer (BS).

\section{Data Extraction}

137 Data extraction was completed by a single reviewer (LFO) using a standardised and pre-piloted data extraction form with Microsoft Excel, and the extraction was verified by a second reviewer (BS). The following information was extracted: (i) author and publication year, (ii) study design; (iii) sample population; (iv) intervention protocol; (v) exercise protocol (vi) blood and exercise outcome data. Where numerical data were not directly available, blood (Bishop \& 
Claudius, 2005; Bishop, Edge, Davis, \& Goodman, 2004; Kozak-Collins, Burke, \& Schoene, 1994; Tan et al., 2010) data were extracted from figures using digitizing software (DigitizeIt; (Rakap, Rakap, Evran, \& Cig, 2016). To avoid duplication bias, when an exercise protocol resulted in multiples outcome measures of the same exercise test, a solitary outcome measure was extracted based upon the following hierarchy: i) total work done; ii) mean output throughout the test (i.e., mean power output; mean velocity; mean height); time-to-completion (performance test)/time to exhaustion (capacity test).

\section{Statistical Analysis}

All meta-analyses (performed by PAS) were conducted within a Bayesian framework to provide a more flexible modelling approach and enable results to be interpreted intuitively through reporting of subjective probabilities (Kruschke \& Liddell, 2018). The first metaanalysis pooled group pre- and post-supplement blood bicarbonate data, with placebocontrolled mean change effect sizes used to summarise findings reported in the actual units of measurement. The second meta-analysis pooled group exercise performance data, with effect sizes calculated by standardising the mean difference in the supplementation and placebo conditions by the placebo standard deviation. Sampling variances of effect sizes required an estimate of the correlation between paired data that are generally not provided in studies. To account for this, an initial estimate was made assuming a correlation of 0.7 and an informative Gaussian prior approximating a correlation between 0.5 and 1 were included. A correction for small sample sizes was applied for both the effect size and its within study variance (Morris \& DeShon, 2002). To investigate the potential for a moderating effect of exercise duration, binary

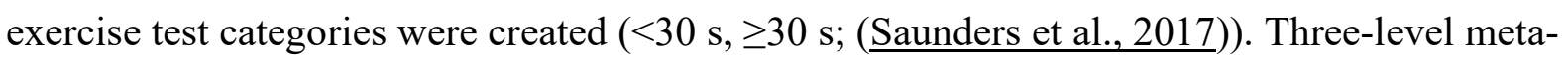
analytic models were used to account for the inclusion of multiple outcomes within a single study (Van den Noortgate, Lopez-Lopez, Marin-Martinez, \& Sanchez-Meca, 2013). 
167 Inferences were performed on posterior samples generated using the Hamiltonian Markov 168 Chain Monte Carlo method, reporting median values and 95\% credible intervals (CrIs). 169 Heterogeneity in the data was quantified by the between study variance parameter which in 170 Bayesian meta-analysis includes uncertainty described by the CrI. Additionally, probabilities 171 were calculated for pooled effect sizes exceeding the threshold of $5 \mathrm{mmol} \cdot \mathrm{L}^{-1}[P($ Increase $>5)]$ 172 for blood bicarbonate (Jones et al., 2016); and exceeding effect sizes (ES) of 0, 0.2 and 0.5 173 (zero, small and medium) $[\mathrm{P}($ Increase $>$ ES)] for exercise outcomes. Probabilities were 174 calculated using the posterior samples of the parameters and the proportion of values exceeding 175 the specified threshold. Due to the small number of data points and potential for small-study 176 effects, sensitivity analyses were completed using robust meta-analyses with random effect 177 fitted with a t-distribution. Funnel plots were not explored due to limited data and consistency 178 across study sample sizes. Analyses were performed using the $\mathrm{R}$ wrapper package brms interfaced with Stan to perform sampling (Bürkner, 2017). 
181 Study search

182 A total of 149 SB articles were identified following the search and filter (Figure 1), of which $183113(76 \%)$ recruited men only and $9(6 \%)$ women only. A total of 21 studies $(14 \%)$ recruited 184 both men and women, 2 of which separated according to sex for analyses, and 19 of which did 185 not, grouping data for both men and women. Six (4\%) studies did not specify the sex of their 186 participants. This resulted in a total of 1175 men and 134 women analysed separately. Studies 187 that analysed men and women together comprised 273 individuals, of which 195 were men and 18878 were women. Of the 30 studies including women, only one reported information relating to 189 the menstrual cycle or contraceptive use of the participants (Macutkiewicz \& Sunderland, 190 2018), with the same study the only to control for menstrual cycle phase during the testing 191 period. Only 11 studies with standalone female groups were taken forward to the meta-analysis. 

SPORTDiscus (470)

Title and abstract screened $(\mathrm{n}=3287)$

Full-text articles assessed for eligibility $(\mathrm{n}=293)$

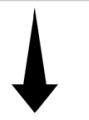

Total sodium bicarbonate articles $(\mathrm{n}=149)$

Studies with men only (113); Studies with women only (9); Studies with mixed sex (21); Studies that did not report sex $(6)$

Studies included in the meta-analysis $(n=10)$

Figure 1. Preferred Reporting Items for Systematic Reviews and Meta-Analyses (PRISMA) guidelines flow chart for literature search and study selection.

\section{Meta-analysis}

Data from ten studies that contained separate data for women were included in the metaanalysis (Table 1). One parallel group study was not included in the analysis since it involved chronic SB or placebo supplementation in female students prior to interval training performed three times per week for eight weeks, but did not involve supplementation prior to the exercise outcome test (Edge, Bishop, \& Goodman, 2006).

\section{Blood bicarbonate}

Blood bicarbonate data were available from four studies (Bishop \& Claudius, 2005; Bishop, Edge, \& Goodman, 2004; McNaughton et al., 1997; Tan et al., 2010) totalling 39 participants. Results indicated a pooled blood bicarbonate increase of 7.4 [95\% CrI: 4.2 to $10.4 \mathrm{mmol} \cdot \mathrm{L}^{-1}$; $P($ Increase $>5)=0.937$ ] following supplementation. The between study variance was 3.7 
[95\% CrI: 2.2 to $7.8 \mathrm{mmol} \cdot \mathrm{L}^{-1}$ ]. Median values and probabilities remained unchanged in the sensitivity analysis conducted with all data points and robust variance estimation.

Exercise data

212 Twelve exercise outcomes were obtained from ten studies (Bishop \& Claudius, 2005; Bishop, Edge, Davis, et al., 2004; Delextrat et al., 2018; Durkalec-Michalski et al., 2020;

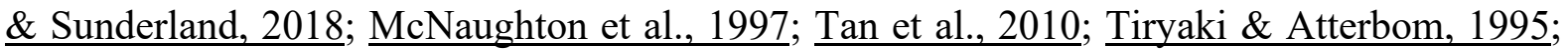
Voskamp et al., 2020) totalling 109 participants. Results indicated a pooled standardised effect size of 0.37 [95\%CrI: -0.06 to $0.92 ; P($ Increase $>0)=0.962 ; P($ Increase $>0.2)=0.784$; $P($ Increase $>0.5)=0.263$; Figure 2] and a between study variance of 0.38 [95\%CrI: 0.02 to 1.2]. Sensitivity analysis with the robust $\mathrm{t}$-distribution to account for the small number of data points and existence of some large individual effects sizes estimated a slightly smaller pooled effect size $0.29[95 \% \mathrm{CrI}:-0.07$ to $0.84 ; P($ Increase $>0)=0.949 ; P($ Increase $>0.2)=0.689$; $P($ Increase $>0.5)=0.191]$. Meta-regression provided no substantive evidence of a moderating effect of exercise duration, with the estimated difference between short $(<30 \mathrm{~s} ; 5$ studies, $\mathrm{n}=54)$ and longer duration ( $\geq 30 \mathrm{~s} ; 6$ studies, $\mathrm{n}=71$ ) exercise tests estimated to be 0.02 [95\%CrI: -0.52 to $0.55 ; \mathrm{P}($ Difference $>0)=0.526]$.

225

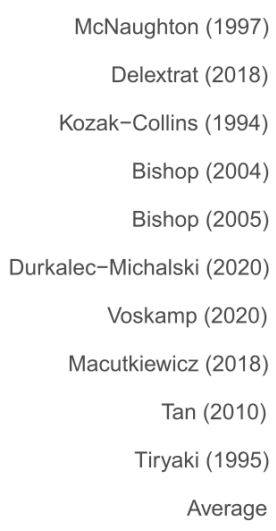

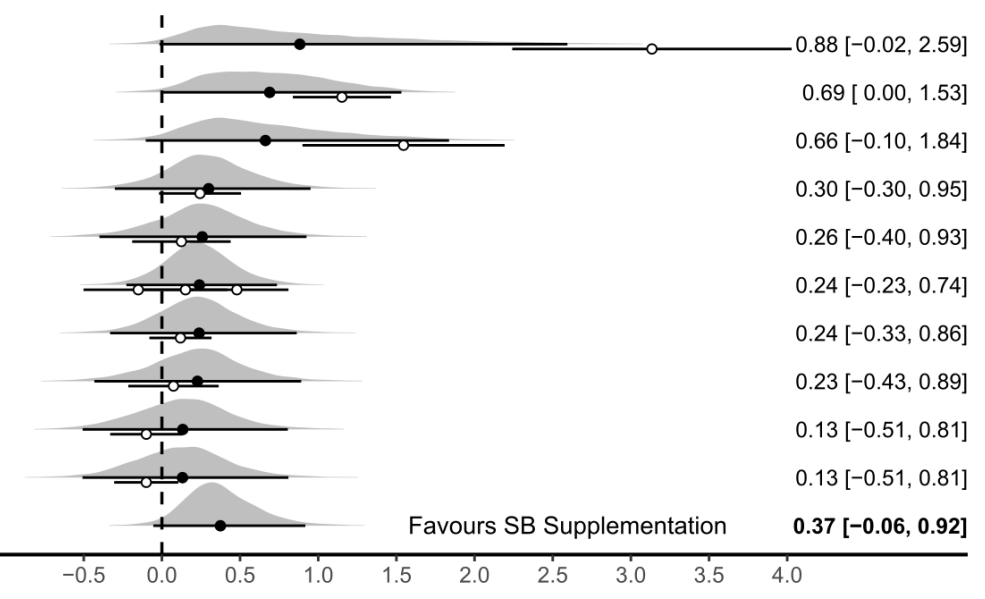

Effect Size 
Figure 2. Bayesian Forest Plot of effect sizes for sodium bicarbonate (SB) supplementation on exercise performance. Distributions represent "shrunken estimates" based on all effects size obtained from the study, the random effects model fitted and borrowed information across studies to reduce uncertainty. Black circles and connected intervals represent the median value and $95 \%$ credible intervals for the shrunken estimates. White circles and intervals represent the raw estimates and sampling variance calculated directly from study data.

Certainty in cumulative outcomes

Blood and exercise outcomes were assigned an a-priori certainty rating of "high" because they were all based on data from blinded, randomized, placebo-controlled trials (as defined by the concerns" according to ROB2 (Figure 3). Three studies had some concerns in Domain 4 (Measurement of the outcome) due to a lack of familiarisation to the protocol (Kozak-Collins et al., 1994; McNaughton et al., 1997) or a non-double-blind study design (Macutkiewicz \&

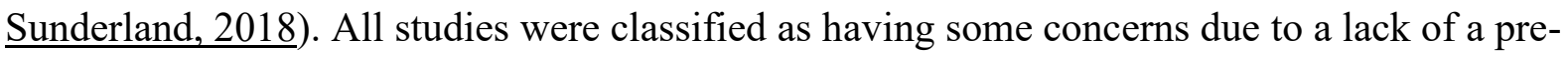
specified analysis plan (as outlined in Domain 5). This was not deemed to pose an undue risk to either outcome measure, thus no outcome was downgraded based on risk of bias (Supplementary Table 1). 


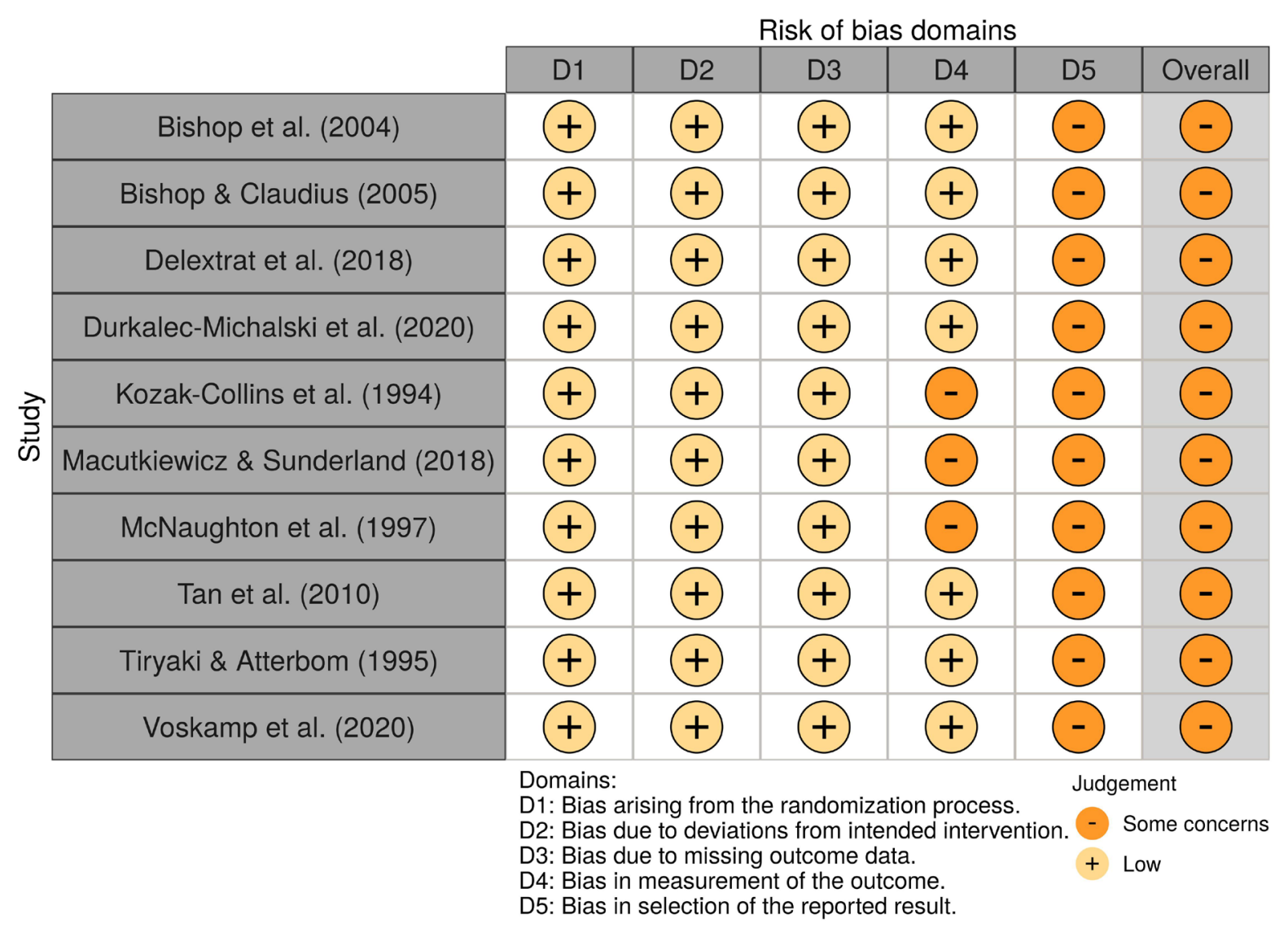

Figure 3. Risk of bias assessment of the ten studies included in the meta-analysis. (Plot was created using robvis (McGuinness \& Higgins, 2020) and are in a colourblind-friendly colour scheme).

Both blood and exercise outcomes were downgraded for imprecision due to low numbers of outcome measures (four for blood, 12 for exercise). Consistent blood and exercise effects meant no measure was downgraded for inconsistency. Almost all studies were performed in young, trained women with commonly employed dosing strategies and, thus, deemed to have direct, real-life applicability for the female athlete and were not downgraded for indirectness. Nonetheless, downgrading of certainty based on indirectness may be advisable for those interested in other populations (e.g., middle-aged, or elderly populations) or exercise outcomes (e.g., resistance/strength exercise). Publication bias was not explored due to limited data and consistency across study sample sizes, meaning no outcome was downgraded for this domain but future meta-analyses with a larger number of studies will allow this to be ascertained. Blood outcomes were upgraded according to GRADE recommendations because they were consistent 
261 with previous meta-analytic results based on the blood bicarbonate response to SB 262 supplementation (Carr et al., 2011) and align with evidence-based and plausible physiological 263 mechanisms. Certainty in exercise outcomes were not upgraded. Thus, certainty in blood 264 outcomes was considered high, and certainty in exercise outcomes considered moderate 265 (Supplementary Table 1). 


\section{Discussion}

267 The SB literature is skewed regarding investigations in women, with only $20 \%$ (30 studies) of studies employing female participants, of which only 11 studies $(7.4 \%)$ provided group analyses exclusively in women. Despite the small amount of available data, results are consistent in showing that SB supplementation in women leads to large changes in blood bicarbonate and that there is strong evidence for a positive ergogenic effect on exercise performance $[P($ Increase $>0)=0.962]$. Due to the small amount of data available and the substantive heterogeneity, it was not possible to obtain a precise estimate of the pooled effect size for exercise performance. However, the analyses suggest the effect is most likely to be between small and moderate.

Research on exercise physiology and nutritional supplements in women is notoriously scarce (Burke, 2017; O'Halloran, 2020), and the SB literature is no different with only 11 of 149 studies including a standalone female group. Across the whole research base comprising men and women, strong evidence exists to support the use of SB to improve exercise outcomes as demonstrated by multiple meta-analyses (Carr et al., 2011; Christensen et al., 2017; Matson \& Tran, 1993; Peart et al., 2012). The current meta-analytical data restricted to female participants and based on nine crossover studies and one parallel group design comprising 118 participants is consistent with previous evidence. Whilst uncertainty in the pooled effect size was high due to the limited number of data points and substantive heterogeneity across studies, the probability that the pooled effect size was small or above was estimated to be around $78 \%$, and the median standardised estimate of 0.37 is consistent with previous research conducted with predominantly male participants $(0.36-0.44)$ (Christensen et al., 2017; $\underline{\text { Matson \& Tran, } 1993}$; Peart et al., 2012). 
The recent data of Durkalec-Michalski et al. (2020) showed that SB supplementation improved wrestling specific performance in men, but not women. The authors speculated that physiological factors that might explain these divergent responses include differences in muscle fibre type and anaerobic capacity. Women typically have less overall muscle mass ( $\underline{\text { Hegge et al., 2016}}$; Janssen et al., 2000), type II muscle fibres (Porter et al., 2002; $\underline{\text { Simoneau }}$ $\underline{\& \text { Bouchard, 1989) }}$ and lower glycolytic capacity (Green et al., 1984; $\underline{\text { Russ et al., 2005; }}$ Tarnopolsky, 2000), meaning they might be less susceptible to performance affecting decreases in muscle $\mathrm{pH}$ and, thus, also less susceptible to performance improvements with increased buffering capacity. The results of this study contrast with this hypothesis and the results of Durkalec-Michalski et al. (2020) and suggest that women do benefit from SB supplementation. This discrepancy might be due to a low sample size in Durkalec-Michalski et al. (2020) which was potentially unable to detect small differences in performance of these exercise tests. The number of women in their study was almost half that of men (18 vs. 33), and although women showed no improvements while men did, performance changes for women appear similar to those of men (Figure 3 of the original article).

Some evidence indicates that menstrual cycle phase may impact anaerobic exercise capacity, with reduced performance previously observed in the early follicular phase of the menstrual cycle (Masterson, 1999), although other studies failed to replicate this finding (Bushman, Masterson, \& Nelsen, 2006; Sunderland \& Nevill, 2003; Sunderland, Tunaley, Horner,

Harmer, \& Stokes, 2011). Greater evidence for no effect of menstrual cycle is consistent with recent meta-analytic data that indicated that exercise test performance may be only trivially reduced during the early follicular phase of the menstrual cycle (McNulty et al., 2020), although it is important to highlight that the observed effect was very small, and varied widely across studies. Nonetheless, these data indicating a potential difference in exercise performance 
across the menstrual cycle could also be taken to imply that the efficacy of ergogenic aids intended to enhance exercise test performance may also be impacted by menstrual cycle phase, particularly at the individual level. Despite this, only one of the 11 studies included within this review reported information relative to menstrual cycle/contraceptive use and to standardisation of tests (or not) according to menstrual cycle phase. Macutkiewicz and Sunderland (2018) reported that seven of their eight participants had normal menstrual cycles while one had been taking an oral contraceptive for over a year. The two experimental trials in this study were conducted during days 4-14 of the follicular phase or during days 5-20 of resuming the oral contraceptive pill. This was verified by measuring plasma progesterone concentrations, which were not different between trials, although it is important to highlight that progesterone levels remain relatively stable during the follicular phase of the menstrual cycle, whereas oestrogen increases rapidly meaning that different oestrogen concentrations between trials cannot be ruled out. Currently, no information exists as to whether menstrual cycle phase would alter the physiological and exercise responses to SB supplementation. However, considering the effects of ergogenic supplements are generally small, even very small changes in exercise capacity during different phases of the menstrual cycle (McNulty et al., 2020) may potentially modify these effects and this warrants investigation.

Most studies included here provided an acute $0.3-0.4 \mathrm{~g} \cdot \mathrm{kg}^{-1} \mathrm{BM}$ dose of SB in the $180-90$ min prior to exercise, although two provided SB chronically (Delextrat et al., 2018; DurkalecMichalski et al., 2020). These acute supplementation protocols are most commonly applied in the literature and also appear to be the most effective (Heibel et al., 2018). Overall, the effect on exercise is likely to be between small to medium in magnitude, which is consistent with what we currently know about the influence of SB in men. Based on these findings, we do not believe there is any evidence to support sex-specific SB dosing recommendations and that 
current recommendations of $0.2-0.3 \mathrm{~g} \cdot \mathrm{kg}^{-1} \mathrm{BM}$ of SB taken $60-180 \mathrm{~min}$ prior to highintensity exercise (de Oliveira, Saunders, Yamaguchi, Swinton, \& Artioli, 2020) appear appropriate for the female athlete.

This meta-analysis is somewhat limited by the low number of included articles and exercise outcomes, with only four studies reporting pre- to post-supplementation blood bicarbonate changes and twelve exercise outcomes. Nonetheless, evidence for large changes in blood bicarbonate was very strong and certainty in this outcome was high. Although certainty in exercise outcomes was only moderate, there was strong evidence that effects on exercise outcomes was greater than zero. This is further supported by individual study data, all of which suggests very small to large positive effects (Figure 2). Sodium bicarbonate supplementation has been shown to improve muscular endurance, but not muscular strength (Grgic et al., 2020). However, none of the included studies here measured muscular strength or endurance and, thus, any conclusions must be limited to these predominantly aerobic and anaerobic exercise protocols. Finally, these data are highly applicable for trained young women since most studies employed trained or elite female athletes with an average age across these studies of $19-26$ years. The generalisability of these conclusions to middle-aged or elderly populations is currently less certain.

In conclusion, the scientific literature regarding the efficacy of SB on exercise performance is highly biased towards male participants. The limited data in women does provide evidence of a small to medium positive effect of supplementation on exercise performance. 
Allen, D. G., Lamb, G. D., \& Westerblad, H. (2008). Skeletal muscle fatigue: cellular mechanisms. Physiol Rev, 88(1), 287-332. doi: 10.1152/physrev.00015.2007

Bishop, D., \& Claudius, B. (2005). Effects of induced metabolic alkalosis on prolonged intermittent-sprint performance. Med Sci Sports Exerc, 37(5), 759-767

Bishop, D., Edge, J., Davis, C., \& Goodman, C. (2004). Induced metabolic alkalosis affects muscle metabolism and repeated-sprint ability. Med Sci Sports Exerc, 36(5), 807-813

Bishop, D., Edge, J., \& Goodman, C. (2004). Muscle buffer capacity and aerobic fitness are associated with repeated-sprint ability in women. Eur J Appl Physiol, 92(4-5), 540-547. doi: 10.1007/s00421-004-1150-1

Burke, L. M. (2017). Practical Issues in Evidence-Based Use of Performance Supplements: Supplement Interactions, Repeated Use and Individual Responses. Sports Med, 47(Suppl 1), 79-100. doi: 10.1007/s40279-017-0687-1

Bürkner, P.-C. (2017). brms: An R Package for Bayesian Multilevel Models Using Stan. Journal of Statistical Software, 80(1), 28. doi: 10.18637/jss.v080.i01

Bushman, B., Masterson, G., \& Nelsen, J. (2006). Anaerobic power performance and the menstrual cycle: eumenorrheic and oral contraceptive users. J Sports Med Phys Fitness, 46(1), 132-137

Carr, A. J., Hopkins, W. G., \& Gore, C. J. (2011). Effects of acute alkalosis and acidosis on performance: a meta-analysis. Sports Med, 41(10), 801-814. doi: 10.2165/11591440000000000-00000

Christensen, P. M., Shirai, Y., Ritz, C., \& Nordsborg, N. B. (2017). Caffeine and Bicarbonate for Speed. A Meta-Analysis of Legal Supplements Potential for Improving Intense Endurance Exercise Performance. Front Physiol, 8, 240. doi: 10.3389/fphys.2017.00240

de Oliveira, L. F., Saunders, B., Yamaguchi, G., Swinton, P., \& Artioli, G. G. (2020). Is Individualization of Sodium Bicarbonate Ingestion Based on Time to Peak Necessary? Medicine \& Science in Sports \& Exercise, 52(8), 1801-1808. doi: 10.1249/MSS.0000000000002313

Delextrat, A., Mackessy, S., Arceo-Rendon, L., Scanlan, A., Ramsbottom, R., \& CallejaGonzalez, J. (2018). Effects of Three-Day Serial Sodium Bicarbonate Loading on Performance and Physiological Parameters During a Simulated Basketball Test in Female University Players. Int J Sport Nutr Exerc Metab, 28(5), 547-552. doi: 10.1123/ijsnem.2017-0353

Durkalec-Michalski, K., Zawieja, E. E., Zawieja, B. E., Michalowska, P., \& Podgorski, T. (2020). The gender dependent influence of sodium bicarbonate supplementation on anaerobic power and specific performance in female and male wrestlers. Sci Rep, 10(1), 1878. doi: 10.1038/s41598-020-57590-x

Edge, J., Bishop, D., \& Goodman, C. (2006). Effects of chronic NaHCO3 ingestion during interval training on changes to muscle buffer capacity, metabolism, and short-term endurance performance. J Appl Physiol (1985), 101(3), 918-925. doi: 10.1152/japplphysiol.01534.2005

Fitts, R. H. (1994). Cellular mechanisms of muscle fatigue. Physiol Rev, 74(1), 49-94

Green, H. J., Fraser, I. G., \& Ranney, D. A. (1984). Male and female differences in enzyme activities of energy metabolism in vastus lateralis muscle. J Neurol Sci, 65(3), 323-331. doi: 10.1016/0022-510x(84)90095-9

Grgic, J., Rodriguez, R. F., Garofolini, A., Saunders, B., Bishop, D. J., Schoenfeld, B. J., \& Pedisic, Z. (2020). Effects of Sodium Bicarbonate Supplementation on Muscular 
Strength and Endurance: A Systematic Review and Meta-analysis. Sports Med, 50(7), 1361-1375. doi: 10.1007/s40279-020-01275-y

Guyatt, G. H., Oxman, A. D., Vist, G. E., Kunz, R., Falck-Ytter, Y., Alonso-Coello, P., . . . Group, G. W. (2008). GRADE: an emerging consensus on rating quality of evidence and strength of recommendations. BMJ, 336(7650), 924-926. doi: 10.1136/bmj.39489.470347.AD

Hegge, A. M., Bucher, E., Ettema, G., Faude, O., Holmberg, H. C., \& Sandbakk, O. (2016). Gender differences in power production, energetic capacity and efficiency of elite crosscountry skiers during wholebody, upperbody, and arm poling. Eur J Appl Physiol, 116(2), 291-300. doi: 10.1007/s00421-015-3281-y

Heibel, A. B., Perim, P. H. L., Oliveira, L. F., McNaughton, L. R., \& Saunders, B. (2018). Time to Optimize Supplementation: Modifying Factors Influencing the Individual Responses to Extracellular Buffering Agents. Front Nutr, 5, 35. doi: $10.3389 /$ fnut.2018.00035

Janssen, I., Heymsfield, S. B., Wang, Z. M., \& Ross, R. (2000). Skeletal muscle mass and distribution in 468 men and women aged 18-88 yr. J Appl Physiol (1985), 89(1), 8188. doi: $10.1152 /$ jappl.2000.89.1.81

Jarvis, K., Woodward, M., Debold, E. P., \& Walcott, S. (2018). Acidosis affects muscle contraction by slowing the rates myosin attaches to and detaches from actin. $J$ Muscle Res Cell Motil. doi: 10.1007/s10974-018-9499-7

Jones, R. L., Stellingwerff, T., Artioli, G. G., Saunders, B., Cooper, S., \& Sale, C. (2016). Dose-Response of Sodium Bicarbonate Ingestion Highlights Individuality in Time Course of Blood Analyte Responses. Int J Sport Nutr Exerc Metab, 26(5), 445-453. doi: 10.1123/ijsnem.2015-0286

Kozak-Collins, K., Burke, E. R., \& Schoene, R. B. (1994). Sodium bicarbonate ingestion does not improve performance in women cyclists. Med Sci Sports Exerc, 26(12), 1510-1515

Kruschke, J. K., \& Liddell, T. M. (2018). The Bayesian New Statistics: Hypothesis testing, estimation, meta-analysis, and power analysis from a Bayesian perspective. Psychon Bull Rev, 25(1), 178-206. doi: 10.3758/s13423-016-1221-4

Macutkiewicz, D., \& Sunderland, C. (2018). Sodium bicarbonate supplementation does not improve elite women's team sport running or field hockey skill performance. Physiol Rep, 6(19), e13818. doi: 10.14814/phy2.13818

Masterson, G. (1999). The Impact of Menstrual Phases on Anaerobic Power Performance in Collegiate Women. The Journal of Strength \& Conditioning Research, 13(4), 325-329

Matson, L. G., \& Tran, Z. V. (1993). Effects of sodium bicarbonate ingestion on anaerobic performance: a meta-analytic review. Int J Sport Nutr, 3(1), 2-28

Maughan, R. J., Burke, L. M., Dvorak, J., Larson-Meyer, D. E., Peeling, P., Phillips, S. M., . . . Engebretsen, L. (2018). IOC consensus statement: dietary supplements and the highperformance athlete. Br J Sports Med, 52(7), 439-455. doi: 10.1136/bjsports-2018099027

McGuinness, L. A., \& Higgins, J. P. T. (2020). Risk-of-bias VISualization (robvis): An R package and Shiny web app for visualizing risk-of-bias assessments. Research Synthesis Methods, $n / a(\mathrm{n} / \mathrm{a})$. doi: $10.1002 / \mathrm{jrsm} .1411$

McNaughton, L. R., Ford, S., \& Newbold, C. (1997). Effect of Sodium Bicarbonate Ingestion on High Intensity Exercise in Moderately Trained Women. The Journal of Strength \& Conditioning Research, 11(2), 98-102

McNulty, K. L., Elliott-Sale, K. J., Dolan, E., Swinton, P. A., Ansdell, P., Goodall, S., . . . Hicks, K. M. (2020). The Effects of Menstrual Cycle Phase on Exercise Performance in Eumenorrheic Women: A Systematic Review and Meta-Analysis. Sports Med, 50(10), 1813-1827. doi: 10.1007/s40279-020-01319-3 
Moher, D., Liberati, A., Tetzlaff, J., Altman, D. G., \& Group, P. (2009). Preferred reporting items for systematic reviews and meta-analyses: the PRISMA statement. Ann Intern Med, 151(4), 264-269, W264

Morris, S. B., \& DeShon, R. P. (2002). Combining effect size estimates in meta-analysis with repeated measures and independent-groups designs. Psychol Methods, 7(1), 105-125. doi: 10.1037/1082-989x.7.1.105

O'Halloran, K. D. (2020). Mind the gap: widening the demographic to establish new norms in human physiology. J Physiol. doi: 10.1113/JP279986

Ouzzani, M., Hammady, H., Fedorowicz, Z., \& Elmagarmid, A. (2016). Rayyan-a web and mobile app for systematic reviews. Systematic Reviews, 5(1), 210. doi: 10.1186/s13643-016-0384-4

Peart, D. J., Siegler, J. C., \& Vince, R. V. (2012). Practical recommendations for coaches and athletes: a meta-analysis of sodium bicarbonate use for athletic performance. $J$ Strength Cond Res, 26(7), 1975-1983. doi: 10.1519/JSC.0b013e3182576f3d

Porter, M. M., Stuart, S., Boij, M., \& Lexell, J. (2002). Capillary supply of the tibialis anterior muscle in young, healthy, and moderately active men and women. $J$ Appl Physiol (1985), 92(4), 1451-1457. doi: 10.1152/japplphysiol.00744.2001

Rakap, S., Rakap, S., Evran, D., \& Cig, O. (2016). Comparative evaluation of the reliability and validity of three data extraction programs: UnGraph, GraphClick, and DigitizeIt. Computers in Human Behavior, 55, 159-166. doi: https://doi.org/10.1016/j.chb.2015.09.008

Russ, D. W., Lanza, I. R., Rothman, D., \& Kent-Braun, J. A. (2005). Sex differences in glycolysis during brief, intense isometric contractions. Muscle Nerve, 32(5), 647-655. doi: 10.1002/mus.20396

Saunders, B., Elliott-Sale, K., Artioli, G. G., Swinton, P. A., Dolan, E., Roschel, H., . . . Gualano, B. (2017). $\beta$-alanine supplementation to improve exercise capacity and performance: a systematic review and meta-analysis. Br J Sports Med, 51(8), 658-669. doi: 10.1136/bjsports-2016-096396

Simoneau, J. A., \& Bouchard, C. (1989). Human variation in skeletal muscle fiber-type proportion and enzyme activities. Am J Physiol, 257(4 Pt 1), E567-572. doi: 10.1152/ajpendo.1989.257.4.E567

Sterne, J. A. C., Savovic, J., Page, M. J., Elbers, R. G., Blencowe, N. S., Boutron, I., . . . Higgins, J. P. T. (2019). RoB 2: a revised tool for assessing risk of bias in randomised trials. $B M J, 366,14898$. doi: 10.1136/bmj.14898

Sundberg, C. W., Hunter, S. K., Trappe, S. W., Smith, C. S., \& Fitts, R. H. (2018). Effects of elevated $\mathrm{H}(+)$ and $\mathrm{Pi}$ on the contractile mechanics of skeletal muscle fibres from young and old men: implications for muscle fatigue in humans. J Physiol, 596(17), 3993-4015. doi: 10.1113/JP276018

Sunderland, C., \& Nevill, M. (2003). Effect of the menstrual cycle on performance of intermittent, high-intensity shuttle running in a hot environment. Eur J Appl Physiol, 88(4-5), 345-352. doi: 10.1007/s00421-002-0722-1

Sunderland, C., Tunaley, V., Horner, F., Harmer, D., \& Stokes, K. A. (2011). Menstrual cycle and oral contraceptives' effects on growth hormone response to sprinting. Appl Physiol Nutr Metab, 36(4), 495-502. doi: 10.1139/h11-039

Tan, F., Polglaze, T., Cox, G., Dawson, B., Mujika, I., \& Clark, S. (2010). Effects of induced alkalosis on simulated match performance in elite female water polo players. Int J Sport Nutr Exerc Metab, 20(3), 198-205. doi: 10.1123/ijsnem.20.3.198

Tarnopolsky, M. A. (2000). Gender differences in substrate metabolism during endurance exercise. Can J Appl Physiol, 25(4), 312-327. doi: 10.1139/h00-024 
510 Tiryaki, G. R., \& Atterbom, H. A. (1995). The effects of sodium bicarbonate and sodium citrate on 600 m running time of trained females. J Sports Med Phys Fitness, 35(3), 194-198 Three-level meta-analysis of dependent effect sizes. Behav Res Methods, 45(2), 576594. doi: 10.3758/s 13428-012-0261-6 Effect of Sodium Bicarbonate Supplementation on the Decline in Gross Efficiency During a 2000-m Cycling Time Trial. Int J Sports Physiol Perform, 15(5), 741-747. doi: $10.1123 /$ ijspp.2019-0177 
Table 1. Sodium bicarbonate studies with female participants analysed separately

\begin{tabular}{|c|c|c|c|c|c|}
\hline Authors (Year) & Population & $\begin{array}{c}\text { Supplementation } \\
\end{array}$ & Study Design & Exercise Test & Familiarisation? \\
\hline Bishop et al. (2004) & $\begin{array}{l}\text { Recreational team-sport } \\
\text { playing females }(\mathrm{N}=10)\end{array}$ & $\begin{array}{c}0.3 \mathrm{~g} \cdot \mathrm{kg}^{-1} \mathrm{BM} 90 \mathrm{~min} \text { prior to exercise in } \\
\text { gelatine capsules. } \\
\text { Placebo: } \mathrm{NaCl}\left(0.207 \mathrm{~g} \cdot \mathrm{kg}^{-1} \mathrm{BM}\right)\end{array}$ & $\begin{array}{l}\text { Double-blind, } \\
\text { Crossover }\end{array}$ & $5 \times 6$ s repeated sprint cycling test & Yes \\
\hline $\begin{array}{l}\text { Bishop \& Claudius } \\
\qquad(2005)\end{array}$ & Team-sport athletes $(\mathrm{N}=7)$ & $\begin{array}{c}0.2 \mathrm{~g} \cdot \mathrm{kg}^{-1} \mathrm{BM} 110-90 \mathrm{~min} \text { and } 0.2 \mathrm{~g} \cdot \mathrm{kg}^{-} \\
{ }_{\mathrm{BM}} 50-20 \text { min prior to exercise in } \\
\text { gelatine capsules. } \\
\text { Placebo: } \mathrm{NaCl}\left(2 \times 0.138 \mathrm{~g} \cdot \mathrm{kg}^{-1} \mathrm{BM}\right)\end{array}$ & $\begin{array}{l}\text { Double-blind, } \\
\text { Crossover }\end{array}$ & $\begin{array}{c}\text { Intermittent cycling sprint test } 2 \text { × } 36 \text { min of } 4-s \\
\text { sprints, } 100 \mathrm{~s} \text { active recovery }+20 \mathrm{~s} \text { recovery } \\
\text { passive }\end{array}$ & Yes \\
\hline Delextrat et al. (2018) & $\begin{array}{l}\text { University basketball players } \\
\qquad(\mathrm{N}=15)\end{array}$ & $\begin{array}{l}0.4 \mathrm{~g} \cdot \mathrm{kg}^{-1} \text { BM per day for } 3 \text { days in } \\
\text { gelatine capsules. Final ingestion the } \\
\text { day before the test. } \\
\text { Placebo: } \mathrm{CaCO}_{3}\left(0.4 \mathrm{~g} \cdot \mathrm{kg}^{-1} \mathrm{BM}\right)\end{array}$ & $\begin{array}{l}\text { Double-blind, } \\
\text { Crossover }\end{array}$ & $\begin{array}{l}\text { Basketball simulation test } \\
\text { (repeated sprint and jump performance) }\end{array}$ & Yes \\
\hline Edge et al. (2006) & $\begin{array}{l}\text { Moderately trained students } \\
\text { involved in club level sports } \\
\qquad(\mathrm{N}=16)\end{array}$ & $\begin{array}{l}0.2 \mathrm{~g} \cdot \mathrm{kg}^{-1} \text { BM } 90 \mathrm{~min} \text { and } 0.2 \mathrm{~g} \cdot \mathrm{kg}^{-1} \mathrm{BM} \\
30 \mathrm{~min} \text { prior to training throughout } 8 \\
\text { weeks of training }(3 \mathrm{x} / \mathrm{week}) \\
\text { Placebo: } \mathrm{NaCl}\left(2 \mathrm{x} 0.1 \mathrm{mg} \cdot \mathrm{kg}^{-1} \mathrm{BM}\right)\end{array}$ & $\begin{array}{l}\text { Single-blind, } \\
\text { Parallel groups }\end{array}$ & $\begin{array}{c}\text { Cycling test at } 100 \% \text { of } \mathrm{VO}_{2 \text { peak }} \text { until } \\
\text { exhaustion }\end{array}$ & Yes \\
\hline $\begin{array}{l}\text { Kozak-Collins et al. } \\
\qquad(1994)\end{array}$ & Competitive cyclists $(\mathrm{N}=7)$ & $\begin{array}{l}0.3 \mathrm{~g} \cdot \mathrm{kg}^{-1} \mathrm{BM} 120 \text { min prior to exercise } \\
\text { in gelatine capsules } \\
\text { Placebo: } \mathrm{NaCl}\left(0.207 \mathrm{~g} \cdot \mathrm{kg}^{-1} \mathrm{BM}\right)\end{array}$ & $\begin{array}{l}\text { Double-blind, } \\
\text { Crossover }\end{array}$ & $\begin{array}{l}1 \text { min cycling at } 95 \% \mathrm{VO}_{2 \max }: 1 \text { min recovery } \\
\text { at } 60 \mathrm{~W} \text { (repeated until exhaustion) }\end{array}$ & No \\
\hline Tan et al. (2010) & $\begin{array}{l}\text { Elite water polo players } \\
\qquad(\mathrm{N}=12)\end{array}$ & $\begin{array}{l}0.3 \mathrm{~g} \cdot \mathrm{kg}^{-1} \text { BM } 90 \text { min prior to exercise in } \\
\text { gelatine capsules. } \\
\text { Placebo: Corn flour (undefined dose) }\end{array}$ & $\begin{array}{l}\text { Double-blind, } \\
\text { Crossover }\end{array}$ & $\begin{array}{l}\text { Water polo match simulation test (59 min } \\
\text { protocol with } 56 \times 10 \text {-m maximal-sprint swims) }\end{array}$ & Yes \\
\hline $\begin{array}{l}\text { McNaughton et al. } \\
\text { (1997) }\end{array}$ & $\begin{array}{l}\text { Physically active females } \\
\qquad(\mathrm{N}=10)\end{array}$ & $\begin{array}{l}0.3 \mathrm{~g} \cdot \mathrm{kg}^{-1} \mathrm{BM} 90 \text { min prior to exercise in } \\
\text { solution. } \\
\text { Placebo: } \mathrm{NaCl}\left(0.207 \mathrm{~g} \cdot \mathrm{kg}^{-1} \mathrm{BM}\right)\end{array}$ & $\begin{array}{l}\text { Double-blind, } \\
\text { Crossover }\end{array}$ & Single maximal 1-min cycle effort & No \\
\hline $\begin{array}{l}\text { Tiryaki \& Atterbom } \\
\qquad(1995)\end{array}$ & $\begin{array}{l}\text { Track athletes }(\mathrm{N}=11) \text { and } \\
\text { trained non-athletes }(\mathrm{N}=4)\end{array}$ & $\begin{array}{c}0.3 \mathrm{~g} \cdot \mathrm{kg}^{-1} \mathrm{BM} 150 \text { min prior to exercise } \\
\text { in solution. } \\
\text { Placebo: Sugarless Kool-Aid } \\
\text { (undefined dose) }\end{array}$ & $\begin{array}{l}\text { Double-blind, } \\
\text { Crossover }\end{array}$ & $600 \mathrm{~m}$ running test & Yes \\
\hline $\begin{array}{l}\text { Durkalec-Michalski et al. } \\
\qquad(2020)\end{array}$ & $\begin{array}{l}\text { High-level Polish freestyle } \\
\text { wrestlers }(\mathrm{N}=18)\end{array}$ & $\begin{array}{c}\text { 1-2 days: } 25 \mathrm{mg} \cdot \mathrm{kg}^{-1} \mathrm{BM} ; 3-5 \text { days: } 50 \\
\mathrm{mg} \cdot \mathrm{kg}^{-1} \text { BM; } 6-7 \text { days: } 75 \mathrm{mg} \cdot \mathrm{kg}^{-1} \mathrm{BM} ; 8- \\
10 \text { days: } 100 \mathrm{mg} \cdot \mathrm{kg}^{-1} \mathrm{BM} ; \text { tablets. } \\
\text { Placebo: } \mathrm{NaCl}+ \\
\text { maltodextrin (undefined dose) }\end{array}$ & $\begin{array}{l}\text { Double-blind, } \\
\text { Parallel groups }\end{array}$ & $2 \times$ Wingate bouts and Dummy Throw Test & Yes \\
\hline
\end{tabular}


